\title{
Multiple volcanic episodes of flood basalts caused by thermochemical mantle plumes
}

\author{
Shu-Chuan $\operatorname{Lin}^{1} \&$ Peter E. van Keken ${ }^{1}$
}

The hypothesis that a single mushroom-like mantle plume head can generate a large igneous province within a few million years has been widely accepted ${ }^{1}$. The Siberian Traps at the PermianTriassic boundary ${ }^{2}$ and the Deccan Traps at the CretaceousTertiary boundary ${ }^{3}$ were probably erupted within one million years. These large eruptions have been linked to mass extinctions. But recent geochronological data ${ }^{4-11}$ reveal more than one pulse of major eruptions with diverse magma flux within several flood basalts extending over tens of million years. This observation indicates that the processes leading to large igneous provinces are more complicated than the purely thermal, single-stage plume model suggests. Here we present numerical experiments to demonstrate that the entrainment of a dense eclogite-derived material at the base of the mantle by thermal plumes can develop secondary instabilities due to the interaction between thermal and compositional buoyancy forces. The characteristic timescales of the development of the secondary instabilities and the variation of the plume strength are compatible with the observations. Such a process may contribute to multiple episodes of large igneous provinces.

The time gaps between major events of the large igneous provinces (LIPs) range from a few million to several tens of million years (Fig. 1). A number of previous models have been proposed to explain the episodic plume magmatism. Plume head separation at the $660-\mathrm{km}$ discontinuity ${ }^{12}$ and a secondary instability in non-newtonian fluids ${ }^{13}$

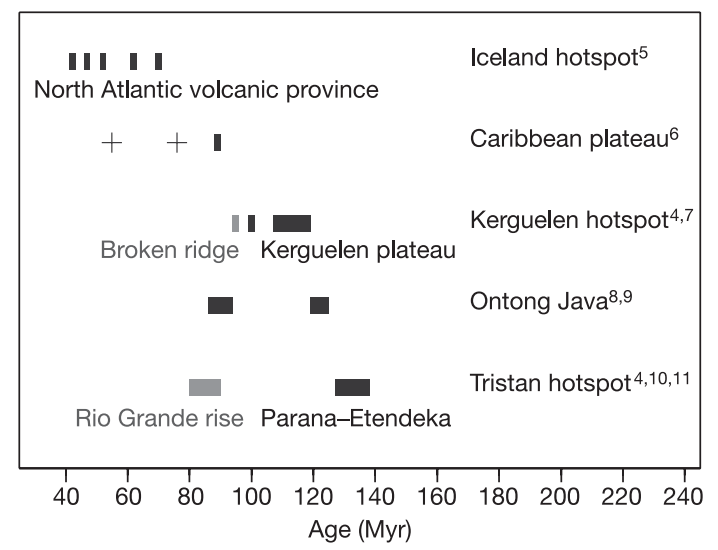

Figure 1 | Summary of the episodic major eruptions of the large igneous provinces in the last $\mathbf{2 0 0}$ million years. Time gaps between the major eruptions range from a few million to several tens of million years. The hotspot tracks for the Tristan and Kerguelen plumes are based on ref. 4. The geochronological data are mainly based on recent ${ }^{40} \mathrm{Ar}^{39} \mathrm{Ar}^{39 t a^{5-11}}$. Black bars mark the major eruptions of the original large igneous provinces. Grey bars show the subsequent major eruption at a distinctive location by the same plumes due to the plate motion. Crosses represent the subsequent episodes sampled in the Caribbean plateau. could both result in the second major event of the LIPs because another plume head is formed at the original plume conduit. But these models do not generate multiple events with irregular time gaps and variable strengths in a plausible time frame. Multiple plume sources or a single dismembered plume has been considered to account for the high flux and diverse geographic distribution of magmatism generated by the Kerguelen plume during 120-95 Myr ago $^{7}$. But multiple mantle sources that are responsible for the formation of a single LIP are not likely to be a global feature. Other models, such as solitary waves travelling along the lowviscosity, thermal plume conduit ${ }^{14}$ and the interaction of magma transport and lithospheric flexure ${ }^{15}$ are proposed to result in the discrete hotspot islands. However, it is unlikely that these mechanisms could cause such large volumes of melts as are observed in discrete LIP events.

Here we examine the evolution of the thermal plumes that entrain dense material at the base of the mantle by a series of highresolution numerical models in an axisymmetric spherical shell. The contribution of dense material by subduction of oceanic crust (eclogite) is favoured by various observations. Seismic studies

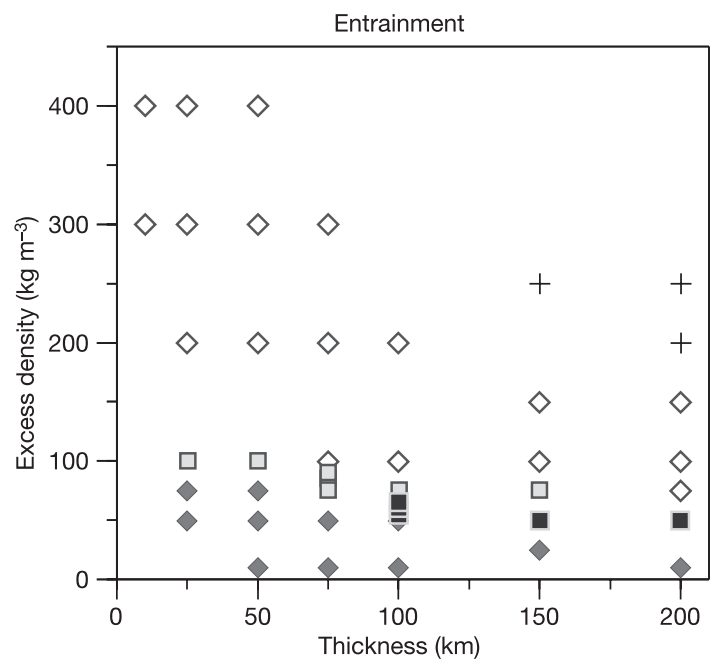

Figure $2 \mid$ Dense layer entrainment for models with $\Delta \eta=10^{2}$. Crosses, stable dense layer; open diamonds, first endmember regime; filled diamonds, second endmember regime; squares, transitional regime; black squares are the models in which the secondary instabilities are developed. The density of eclogite is denser than ambient mantle everywhere except between $670-1,000 \mathrm{~km}$ depth ${ }^{22-24}$. The dense layer is a mixture of various proportions between eclogite and ambient mantle. Other model parameters are the maximum temperature contrast across TBL $(750 \mathrm{~K})$, the ambient mantle viscosity $\left(10^{22} \mathrm{~Pa} \mathrm{~s}\right)$, the reference mantle density $\left(4,000 \mathrm{~kg} \mathrm{~m}^{-3}\right)$, the thermal expansion coefficient $\left(3 \times 10^{-5} \mathrm{~K}^{-1}\right)$, and the thermal diffusivity $\left(10^{-6} \mathrm{~m}^{2} \mathrm{~s}^{-1}\right)$. 

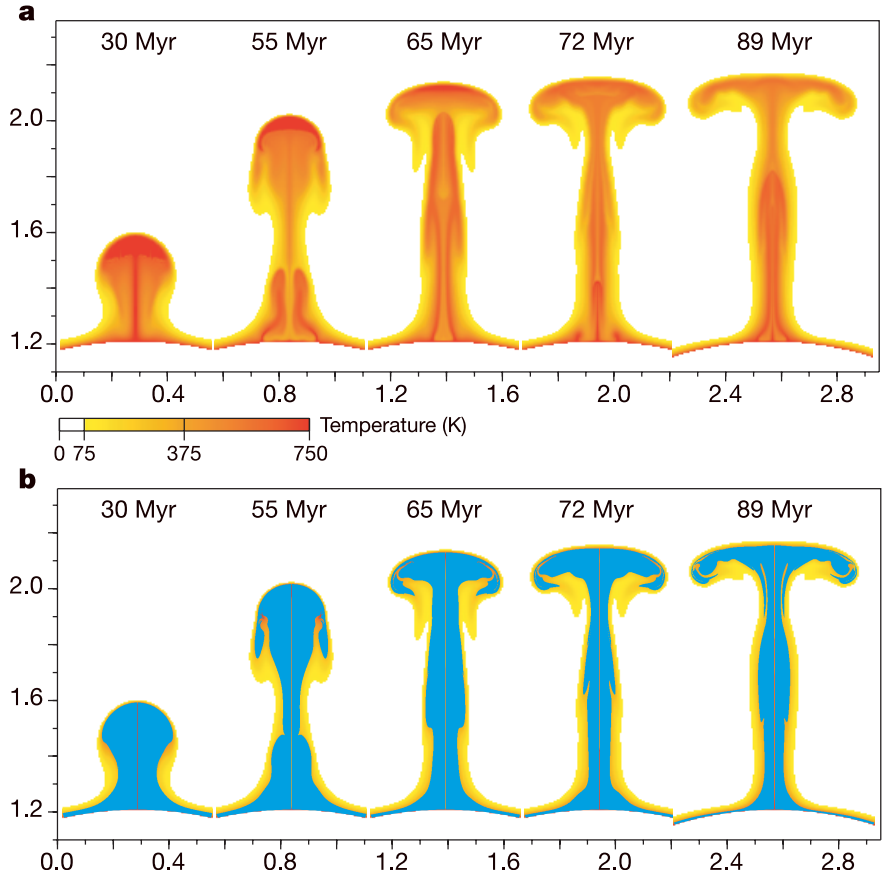

Figure 3 Snapshots showing the evolution of the plume and the development of secondary instabilities. a, Thermal structure.

b, Distribution of the dense material overlying the temperature field. The excess density is $50 \mathrm{~kg} \mathrm{~m}^{-3}$ with an initial thickness of $100 \mathrm{~km}$ for the dense layer and a viscosity contrast $\Delta \eta=10^{3}$. Only the region for the plume formation is shown. Type-I instabilities are generated around $t=55 \mathrm{Myr}$ and $t=89 \mathrm{Myr}$. A type-II instability is generated around $t=72 \mathrm{Myr}$. The length scale is normalized by the thickness of the mantle $(2,885 \mathrm{~km})$. A movie of this model is part of the Supplementary Information.

strongly suggest that many slabs penetrate into the lower mantle and accumulate at the base of the mantle ${ }^{16}$. Oceanic crust material will then contribute to the observed seismic heterogeneity in the lowermost mantle. The presence of the eclogite in the plume source can explain why the flood basalt is iron- and silicate-rich relative to midoceanic ridge basalts ${ }^{17,18}$. The diverse signatures in isotopes of $\mathrm{Nd}, \mathrm{Pb}$ and $\mathrm{Sr}$ of flood basalts can be explained by variable contributions of eclogite to the melt ${ }^{17}$. Studies of the eclogites ${ }^{19}$ and simple mass balance also suggest that a significant volume of the eclogite must enter the lower mantle. To focus on the development of the thermochemical plumes, we consider the simplified model of a single, homogeneous layer of the mixture of eclogite and lowermantle material. This layer is initially stable at the base of the mantle but becomes perturbed by the formation of a thermal plume. Our calculations show that multiple pulses of plume material are natural consequences of a plume system with the presence of the compositionally dense material. We therefore propose that plumes that entrain dense material can cause the discrete phases of major eruptions of flood basalt provinces.

We performed the calculations using the Sepran finite-element package modified for thermochemical convection in a Boussinesq fluid at infinite Prandtl number ${ }^{20}$. The average grid resolution is $\sim 10 \mathrm{~km}$ and the mesh is refined to $2-5-\mathrm{km}$ resolution in the boundary layer and at the plume axis. The distribution of the compositionally distinctive material is modelled by the marker chain method ${ }^{21}$. The core-mantle boundary is represented by a free-slip, isothermal, impermeable lower boundary. The top surface and sidewall are set to be no-slip to avoid the global-scale convection so that we can focus on the evolution of the plumes. A thermal boundary layer (TBL) $130 \mathrm{~km}$ in thickness with a perturbation at the axis and a compositionally distinctive layer with uniform thickness is initiated at the base of the model at $t=0$. The temperature dependence of viscosity is modelled as $\eta=\eta_{0} \exp (-a T)$, where $\eta$ is the viscosity, $\eta_{0}$ is the reference viscosity, $a$ is a positive constant, and $T$ is temperature. We examine models with maximum viscosity variations $(\Delta \eta)$ of $10^{2}$ and $10^{3}$, a reference density contrast between $0-400 \mathrm{~kg} \mathrm{~m}^{-3}$ and dense layer thickness of $10-200 \mathrm{~km}$. This parameter range covers the expected variability and uncertainties associated with the boundary layer in the lowermost mantle. Other model parameters can be found in the caption of Fig. 2 and in the Supplementary Information.

Our calculations show that the general features for the dense material entrainment by the thermal plumes can be categorized by two endmember regimes and a transitional regime (Fig. 2). In the first endmember regime, the excess density of the compositional layer is large enough to prevent plume formation from the lower portion of the TBL. The plume is formed from the upper portion of the TBL only, with consequently lower temperature and minor entrainment of dense material. This regime has been explored previously by ref. 25 . In the second endmember regime the thermal effect dominates and the thermal plumes entrain significant volumes of the dense layer with high plume temperature. The regime of interest here occurs when the thermal and chemical buoyancy effects are in near-balance and secondary instabilities occur (Fig. 3).

In the intermediate regime we observe two types of instabilities (Fig. 3). The first (type I) occurs when the plume head rises; dense material drawn by the concentric flow accumulates around the base of the plume axis and induces a counter flow. Flow from the lower portion of the TBL increases the size and thermal buoyancy of the counter flow region. This region eventually becomes unstable and the type-I instability propagates at high speed through the pre-existing plume conduit $(\sim 55-65 \mathrm{Myr})$. The volume of this instability is of the same order of magnitude as that of the original plume head. The disappearance of the counter flow leads to the formation of a new TBL at the base of the main plume and second (type II) instability of small volume but high temperature develops $(\sim 72 \mathrm{Myr})$. This process can be repeated with subsequent formations of type-I ( $\sim 89 \mathrm{Myr})$ and type-II instabilities.
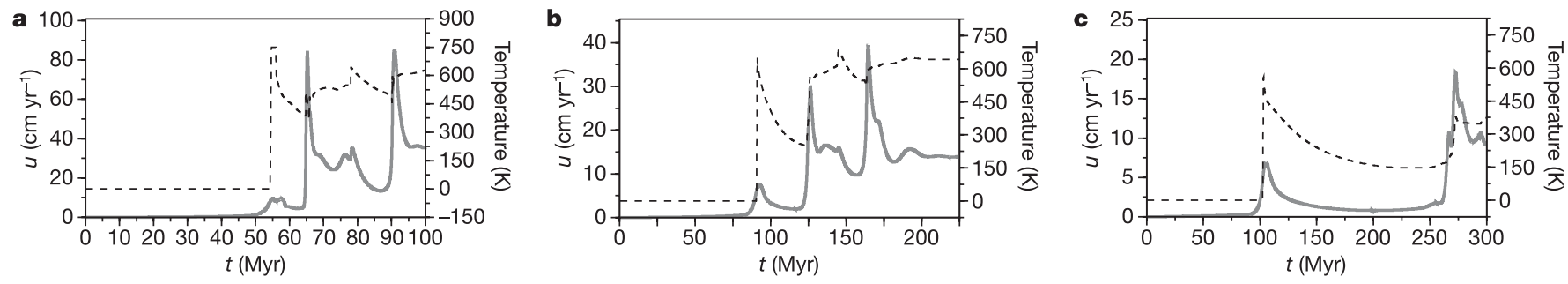

Figure 4 Time evolution of velocity and temperature at the plume axis of 600-km depth for three representative models. Velocity, grey line; temperature, dashed line. The first peak of the velocity is generated by the original plume head. The other large peaks result from the type-I

instabilities. The smaller peaks are due to the type-II instabilities. a, Results

for model in Fig. 3. b, Results for model with $\Delta \eta=10^{2}$, excess density of $60 \mathrm{~kg} \mathrm{~m}^{-3}$ and initial thickness of $100 \mathrm{~m}$ for dense layer. c, Results for model with $\Delta \eta=10^{2}$, an excess density of $50 \mathrm{~kg} \mathrm{~m}^{-3}$, and an initial thickness of $200 \mathrm{~km}$ for dense layer. 
The leading edge of the type-I instabilities propagates at an average speed of about $3-7 \mathrm{~cm} \mathrm{yr}^{-1}$ for the model with $\Delta \eta=10^{2}$ (not shown) and $5-23 \mathrm{~cm} \mathrm{yr}^{-1}$ for models with $\Delta \eta=10^{3}$ (Fig. 3 ). The instantaneous velocity of both types of instabilities can be as high as $10-85 \mathrm{~cm} \mathrm{yr}^{-1}$, which is much higher than the maximum velocity of the original plume head (5-10 $\mathrm{cm} \mathrm{yr}^{-1}$ ) (Fig. 4). The high velocity of the secondary instabilities is probably a consequence of the low viscosity in the pre-existing plume conduit. It is not necessary to invoke other mechanisms such as large-amplitude solitary waves.

The temperature in the plume head initially decreases during ascent until the instabilities arrive (Figs 3,4). The time interval between the formations of the plume head and the first instability is about $10-150$ million years and that between two instabilities is 10-80 million years. The velocity of the original plume is lower than that of the instabilities. Therefore, the time separation between the arrival of the original plume head to the base of the lithosphere and the replenishment by the instabilities is generally shorter than the time interval between the formations of the plume head and the instabilities. It varies from less than 10 million to more than 100 million years. This is compatible with the time intervals of the episodic eruptions of the LIPs (Fig. 1). In addition, we find an acceptable correlation between the differences in the predicted and observed relative volumes. The estimate of the volume of the magma output inevitably involves uncertainty. Nevertheless, it is commonly accepted that the total volume of each LIP is generally greater than $10^{6} \mathrm{~km}^{3}$. In addition, the available data shows that the magma fluxes of the later eruptions are diverse. The volume of the first major eruption is significantly larger than those of the subsequent events in the Caribbean plateau ${ }^{6}$ and the second major eruption is relatively small in Ontong Java ${ }^{8,9}$. In contrast, the magnitudes of the later events are of the same order as that of the initial major phase of the volcanism for the Kerguelen plume ${ }^{7}$ and Parana-Rio Grande rise (Tristan plume $)^{10,11}$. Calculating melt directly from our models is complicated because it depends strongly on the structure and mineralogy of the upper mantle. Instead, we use variations in buoyancy flux as a proxy for the variations in melt volume, which we consider to be reasonable given that the melt formation in the plume head would occur under similar conditions. The time evolution of the buoyancy flux varies in our models but shows a relative range similar to that suggested by the observations (Supplementary Fig. S2).

Our models demonstrate that the multiple episodes of the major eruptions of LIPs can result from the plume with a dense layer. The excess temperature of the plume head in our model is higher than that of plumes in the upper mantle. Several mechanisms, such as the effects due to the entrainment of the surrounding mantle, the lowerviscosity upper mantle, the phase boundary at $660-\mathrm{km}$ discontinuity and the layered density structure at the $\mathrm{D}^{\prime \prime}$ layer, may cause this discrepancy. The viscosity of the plume is poorly known in the lower mantle, but is possibly lower than that in our models. It would lead to an even more unsteady regime and the instabilities would be induced earlier, hence reducing the time gap between the pulses of the plume material.

\section{Received 17 January; accepted 27 April 2005.}

1. Campbell, I. H. \& Griffiths, R. W. Implications of mantle plume structure for the evolution of flood basalts. Earth Planet. Sci. Lett. 99, 79-93 (1990).

2. Renne, P. R., Zichao, Z., Richards, M. A., Black, M. T. \& Basu, A. R. Synchrony and causal relations between Permian-Triassic boundary crises and Siberian flood volcanism. Science 269, 1413-1416 (1995).

3. Courtillot, V. et al. Deccan flood basalts on Cretaceous/Tertiary boundary. Nature 333, 843-846 (1988).

4. Morgan, W. J. in The Sea (ed. Emiliani, C.) Vol. 7, 443-487 (Wiley, New York, 1981).

5. O'Connor, J. M., Stoffers, P., Wijbrans, J. R., Shannon, P. M. \& Morrissey, T Evidence from episodic seamount volcanism for pulsing of the Iceland plume in the past 70 Myr. Nature 408, 954-958 (2000).

6. Revillon, S., Arndt, N. T., Chauvel, C. \& Hallot, E. Geochemical study of ultramafic volcanic and plutonic rocks from Gorgona Island, Colombia: the Plumbing system of an oceanic plateau. J. Petrol. 41, 1127-1153 (2000).

7. Coffin, M. F. et al. Kerguelen hotspot magma output since 130 Ma. J. Petrol. 43, 1121-1139 (2002)

8. Neal, C. R., Mahoney, J. J., Kroenke, L. W., Duncan, R. A. \& Petterson, M. G. in Large Igneous Provinces: Continental, Oceanic, and Planetary Flood Volcanism (eds Mahoney, J. J. \& Coffin, M. F.) 183-216 (Geophys. Monogr. 100, American Geophysical Union, Washington, DC, 1997).

9. Fitton, J. G. \& Godard, M. in Origin and Evolution of the Ontong Java Plateau (eds Fitton, J. F., Mahoney, J. J., Wallace, P. J. \& Saunders, A. D.) 151-178 (Geol. Soc. Spec. Pub. 229, Geological Society, London, 2004).

10. O'Connor, J. M. \& Duncan, R. A. Evolution of the Walvis Ridge-Rio Grande Rise hot spot system: Implications for African and South American Plate motions over plumes. J. Geophys. Res. 95, 17475-17502 (1990).

11. Stewart, K. et al. $3-\mathrm{D},{ }^{40} \mathrm{Ar}-{ }^{39} \mathrm{Ar}$ geochronology in the Parana flood basalt province. Earth Planet. Sci. Lett. 143, 95-109 (1996).

12. Bercovici, D. \& Mahoney, J. Double flood basalts and plume head separation at 660-kilometer discontinuity. Science 266, 1367-1369 (1994).

13. van Keken, P. E. Evolution of starting mantle plumes: a comparison between numerical and laboratory models. Earth Planet. Sci. Lett. 148, 1-14 (1997)

14. Olson, P., Schubert, G. \& Anderson, C. Plume formation in the $D^{\prime \prime}$-layer and the roughness of the core-mantle boundary. Nature 327, 409-413 (1987)

15. Hieronymus, C. F. \& Bercovici, D. Discrete alternating hotspot islands formed by interaction of magma transport and lithospheric flexure. Nature 397, 604-607 (1999)

16. van der Hilst, R. D., Widiyantoro, S. \& Engdahl, E. R. Evidence for deep mantle circulation from global tomography. Nature 386, 578-584 (1997).

17. Condie, K. C. Mantle Plumes and Their Record in Earth History Ch. 3-5 (Cambridge Univ. Press, New York, 2001).

18. Leitch, A. M. \& Davies, G. F. Mantle plumes and flood basalts: Enhanced melting from plume ascent and an eclogite component. J. Geophys. Res. 106, 2047-2060 (2001)

19. Rudnick, R. L., Barth, M., Horn, I. \& McDonough, W. F. Rutile-bearing refractory eclogites: missing link between continents and depleted mantle. Science 287 278-281 (2000).

20. van Keken, P. E. \& Ballentine, C. J. Whole-mantle versus layered mantle convection and the role of a high-viscosity lower mantle in terrestrial volatile evolution. Earth Planet. Sci. Lett. 156, 19-32 (1998).

21. van Keken, P. E. et al. A comparison of methods for the modeling of thermochemical convection. J. Geophys. Res. 102, 22477-22495 (1997).

22. Irifune, T. \& Ringwood, A. E. Phase transformations in subducted oceanic crust and buoyancy relationships at depths of $600-800 \mathrm{~km}$ in the mantle. Earth Planet. Sci. Lett. 117, 101-110 (1993)

23. van Keken, P. E., Karato, S. \& Yuen, D. A. Rheological control of oceanic crust separation in the transition zone. Geophys. Res. Lett. 23, 1821-1824 (1996).

24. Ono, S., Ito, E. \& Katsura, T. Mineralogy of subducted basaltic crust (MORB) from 25 to $37 \mathrm{GPa}$, and chemical heterogeneity of the lower mantle. Earth Planet. Sci. Lett. 190, 57-63 (2001).

25. Farnetani, C. G. Excess temperature of mantle plumes: The role of chemical stratification across D. Geophys. Res. Lett. 24, 1583-1586 (1997).

Supplementary Information is linked to the online version of the paper at www.nature.com/nature.

Acknowledgements This research is supported in part by the National Science Foundation and the National Science Council of Taiwan, Republic of China.

Author Information Reprints and permissions information is available at npg.nature.com/reprintsandpermissions. The authors declare no competing financial interests. Correspondence and requests for materials should be addressed to S. C. L. (skylin@umich.edu). 